\title{
Tratamientos a la población inmigrante en escuelas de nivel medio de Buenos Aires*
}

\author{
Treatments to the immigrant population in middle- \\ schools of Buenos Aires
}

\section{Tratamentos à povoação imigrante em escolas de nível meio de Buenos Aires}

\author{
Mariana Beheran** • Argentina \\ Recibido el 14 de julio de 2011, aceptado el 24 de noviembre de 2011
}

\section{Resumen}

Objetivo: analizar los tratamientos que los docentes de dos escuelas públicas de nivel medio, ubicadas en un barrio de la zona sur de Buenos Aires, construyen respecto de los estudiantes bolivianos y paraguayos que asisten a ellas. Metodología: el trabajo de campo y el análisis de la información recabada se desarrollaron desde una perspectiva etnográfica y comparativa que atienden a numerosas diferencias relativas a las experiencias formativas que tienen lugar en cada una de las escuelas visitadas. Resultados: se señala la pervivencia de prácticas asimilacionistas, la constitución de prácticas de tipo afectivo y la ausencia de prácticas de tipo multicultural, ampliamente difundidas en las escuelas primarias. Conclusiones: más allá de las transformaciones económicas, políticas, sociales y culturales ocurridas a través de la historia, las prácticas educativas asimilacionistas permancen vigentes. En ocasiones, las buenas intenciones de algunos docentes, que manifiestan reconocer la diversidad cultural presente en los espacios escolares, acaban por generar situaciones de marcación del otro que profundizan las situaciones de estigmatización a jóvenes con diversas pertenencias étnicas y orígenes nacionales.

Palabras claves: migración, racismo, polítias de migración, políticas escolares sobre migrantes, integración cultural, España.

* Este artículo presenta avances de una investigación doctoral en curso en el Doctorado en Ciencias Sociales de la Universidad Nacional General Sarmiento (UNGS) y es financiada con una beca doctoral otorgada por el Consejo Nacional de Investigaciones Científicas y Técnicas (CONICET), de la República Argentina, para el período 2007-2012.

** Magíster en Políticas de Migraciones Internacionales (UBA); Socióloga (UBA); Becaria doctoral del Consejo Nacional de Investigaciones Científicas y Técnicas (CONICET), en la Facultad de Agronomía (UBA); Docente de la Facultad de Ciencias Sociales (UBA); Miembro del Programa de Antropología y Educación del Instituto de Ciencias Antropológicas (FFyL - UBA). Buenos Aires, Argentina. Correo electrónico: mbeheran@agro.uba.ar 


\begin{abstract}
Objective: this paper aims at analyzing how the current economic crisis affects social, political and educational discourse and specific proposals on interculturality in the Spaniard and European context. It describes the possibility of the interculturality project in the educational discourse within the model of European citizenship being currently built. It also considers the possibility of building a real and effective racial mixture in society, as expressed in public speeches. This occurs in a society which tries to consolidate a structural defensive wall of mental, social, labor, economic, political and legal orders against diversity and difference. Methodology: most assumed conflicts of cultural difference should be approached from the perspective of conflicts of interests on wealth distribution, participation in power, distribution and participation conditions, beginning by the recovery of the situations inherited from discrimination and domination. Results: at present, the intercultural project, especially in a crisis context, is useless, sterile, and no feasible because it lacks conditions. And this is not a responsibility of involved institutions and organizations, but of the political representatives, because this is not feasible without a budget. Conclusions: the key is avoiding the anchorage of citizens in an official citizenship status by birth or by naturalization. This kind of identity highlights the inability of the liberal proposal to overcome ethnocultural roots of the assumed Republican model of citizenship.
\end{abstract}

Keywords: migration, racism, public policies of migration, school policies against migrants, cultural integration, Spain.

\title{
Resumo
}

Objetivo: analisa se como está afetando o contexto atual a crise econômica os discursos e as propostas sociais, políticas e educativas e sobre o intercultural no âmbito espanhol e europeu. Indaga-se se o projeto intercultural que proclama se nos discursos educativos é possível no atual modelo de cidadania europeu que se está construindo e se traça se e possível construir real e efetivamente uma sociedade mestiça como proclama se nos discursos públicos numa sociedade que está consolidando um muro defensivo estrutural de caráter mental, social, laboral, econômico, político e legal em frente à diversidade e a diferencia. Metodologia: a maior parte dos supostos conflitos de diferencia cultural têm que ser abordados desde a perspectiva previa de conflitos de interesses sobre a distribuição da riqueza, a participação no poder, as condições para essa participação e distribuição, começando pela reparação das situações herdadas de discriminação e dominação. Resultados: o projeto intercultural, hoje por hoje, máxime num contexto de crise, e inútil, estéril, pouco viável porque falta lhe condições e isso não é responsabilidade das instituições e organizações que trabalham no projeto, por o contrario são responsáveis os políticos, porque sem pressupostos é inviável. Conclusões: a chave radica em evitar a ancoragem da cidadania na nacionalidade (tanto por nascimento como por naturalização), uma identidade que põe de relevo a incapacidade da proposta liberal para superar as raízes etno- culturais do pretendido modelo republicano de cidadania.

Palavras-Chaves: migração, racismo, políticas de migração, políticas escolares em frente a migrantes, integração cultural, Espanha.

Para citar este artículo:
Beheran, M. (junio, 2012). Tratamientos a la población inmigrante en escuelas de nivel medio de Buenos Aires. Ánfora, 19 (32), 49 - 68. Universidad Autónoma de Manizales. ISSN 0121-6538. 


\section{Introducción}

En este artículo se presentan algunas reflexiones que se derivan del trabajo de campo de tipo etnográfico realizado en el marco de la investigación doctoral “'A la vida siempre le tuve curiosidad... Siempre quise aprender y hacer cosas pero mi deseo es volver a mi país'. Intersecciones entre experiencias formativas, socializaciones laborales e identificaciones nacionales de jóvenes inmigrantes, y descendientes de inmigrantes, en la ciudad de Buenos Aires". Dado el escaso desarrollo nacional que ha tenido el estudio de la escolaridad de los jóvenes inmigrantes, este trabajo analiza los tratamientos que los docentes de dos escuelas públicas de nivel medio, ubicadas en el barrio Villa Guadalupe $^{1}$ en la zona sur de Buenos Aires, construyen respecto de los estudiantes de origen boliviano y paraguayo que asisten a ellas.

En Argentina, a partir de la década de 1990, han tenido lugar investigaciones referidas a la escolaridad de niños inmigrantes y la mayor parte de ellas ha dado cuenta de la persistencia de prácticas educativas vinculadas al paradigma asimilacionista combinadas con la emergencia de visiones más positivas respecto de la diversidad cultural, asociadas al paradigma del multiculturalismo. A su vez, se han señalado las situaciones de estigmatización que padecen, en numerosas ocasiones, algunos niños en los espacios escolares y el cruce entre prácticas xenófobas con diversas formas de exclusión social (Neufeld y Thisted, 1999, pp. 27-28; Díez y Novaro, 2009, p. 1). Ahora bien, entre los escasos trabajos sobre la escolaridad de inmigrantes en el nivel medio, cabe destacar el realizado por Nobile (2006) que aborda las prácticas discriminatorias que tienen lugar en ese nivel respecto de los estudiantes inmigrantes y la normativa que atañe a la escolaridad de dichos jóvenes. Así, este trabajo se propone contribuir al conocimiento referido a la escolaridad de los jóvenes inmigrantes y, más específicamente, a los tratamientos respecto de esta población que tienen lugar en dos escuelas públicas de nivel medio de Buenos Aires.

\section{Migraciones y educación. Un complejo vínculo}

Las migraciones internacionales han sido un componente fundamental de la historia argentina. Su registro se observa ya en el primer Censo Nacional de Población realizado en el año 1869. Ahora bien, desde los sectores dominantes, históricamente, se ha construido el imaginario referido al carácter europeo de esa migración. Esto ha generado, entre múltiples consecuencias, que más allá de que los inmigrantes limítrofes también hayan sido registrados por aquel primer censo y que se sepa que su presencia en el país es aún anterior, generalmente al hablar de ellos se haga alusión a los nuevos inmigrantes $^{2}$, invisibilizando la antigüedad de su presencia en el territorio nacional.

El nombre del barrio ha sido modificado para preservar el anonimato de los entrevistados.

2 A lo largo de este escrito se utilizan bastardillas para relativizar ciertos conceptos. 
Entre los años 1881 y 1914 arribaron a Argentina alrededor de 4.200.000 personas provenientes, en su mayor parte, del continente europeo. Se trataba, en su mayoría, de hombres jóvenes procedentes de zonas rurales. Sin embargo, entre 1881 y 1910 retornaron a sus países de origen el 36\% de los inmigrantes (Devoto, 2003, p. 247). Con respecto a los procedentes de países limítrofes, Benencia (2003, p. 433) ha señalado que si bien arribaron a Argentina mucho antes de ser registrados a través de los censos, comenzaron a ser mayormente visibilizados a mediados del siglo XX. A partir de aquel momento, la migración limítrofe empezó a satisfacer la demanda de mano de obra de algunos sectores. Un movimiento se dirigió hacia las áreas de frontera, donde los inmigrantes se convirtieron en trabajadores de la zafra y estacionales y otro hacia el Área Metropolitana de Buenos Aires, donde aportaron con su trabajo al crecimiento de la industria manufacturera y los servicios. Vale aclarar que de acuerdo con la información suministrada por los censos, el peso relativo de su flujo sobre el total de la población nunca superó el 3\%.

Durante el siglo XIX, Alberdi y Sarmiento, entre otros, promocionaron la idea de que el desarrollo de Argentina debía enmarcarse dentro de los lineamientos del pujante capitalismo industrial europeo. La economía nacional necesitaba fuerza de trabajo pero, para estos ideólogos, los trabajadores debían ser específicamente originarios de aquel continente, pues había que poblar pero también modernizar el país y se presumía que los inmigrantes traerían, desde allí, las ideas y los saberes de la modernización capitalista. Sin embargo, los trabajadores europeos que llegaban, en su mayor parte, provenían de sectores empobrecidos y contaban con un nivel educacional bajo. La idea motora fue, entonces, la de transformar tanto a criollos como a aquellos inmigrantes europeos que no cumplieran con las pretensiones del proyecto civilizador, en ciudadanos modernos europeizados. Para ello, se colocó un importante énfasis en el rol que debía cumplir la escuela. Desde mediados del siglo XIX la misma se convirtió en uno de los elementos de homogeneización sociocultural más importante ${ }^{1}$. En tal sentido, comenzaron a desarrollarse los trazos del modelo asimilacionista en educación. El mismo pretendía que las diferencias étnicas, nacionales y lingüísticas fueran homogeneizadas a través de un proceso en el que se alcanzara la pérdida de las pertenencias originarias y se incorporaran las de la sociedad dominante. De esta manera, comenzó a construirse un relato referido a la argentinidad que invisibilizó la historia del genocidio indígena y la de los gauchos, en tanto ambos actores eran percibidos, desde el sector dominante, como la barbarie.

La historia migratoria argentina se ha escrito y enseñado, en general, valorando positivamente a aquellos hombres y mujeres procedentes del continente europeo que arribaron masivamente desde mediados del siglo XIX. El romanticismo que encierra

1 Otros de los instrumentos, utilizados con el mismo fin, fueron la instauración del servicio militar y el voto obligatorios.

Para citar este artículo:
Beheran, M. (junio, 2012). Tratamientos a la población inmigrante en escuelas de nivel medio de Buenos Aires. Ánfora, 19 (32), 49 - 68. Universidad Autónoma de Manizales. ISSN 0121-6538. 
la idea, profundamente instalada en el sentido común nacional, referida a que todos descendemos de los barcos, oculta no sólo la ascendencia indígena de buena parte de la población argentina y la presencia de otros colectivos migratorios provenientes de países limítrofes y del continente asiático, así como de esclavos africanos, sino también el tratamiento discriminatorio que recibieron muchos de aquellos inmigrantes europeos en distintos espacios sociales y también, en ocasiones, a través de la implementación de instrumentos legislativos que propiciaron un alto número de encarcelamientos y deportaciones. Efectivamente, la inmigración europea no fue la que había sido imaginada por los ideólogos de la época pues además de no traer consigo los saberes de la industrialización capitalista, en ocasiones, acarreaba con las ideas de transformación social del socialismo y anarquismo europeos (Devoto, 2003, p. 275). De modo que ya en los primeros años del siglo XX se produjo un cambio de percepción acerca de ella, acompañado de un marco legal constituido por las llamadas leyes de Residencia y de Defensa Social ${ }^{1}$.

Si bien a lo largo de la historia, las prácticas educativas han sido elaboradas, generalmente, desde una perspectiva asimilacionista, las transformaciones sociales, económicas, políticas y culturales permitieron que, en ocasiones, fueran modificándose. Durante la década de 1920, el eje central de la política educativa estuvo situado en la recuperación de la tradición hispana, pues el objetivo fue encontrar una matriz que pudiera servir de base identitaria a los hijos de los inmigrantes (que en un porcentaje considerable provenían de España).

Más adelante, en la década de 1930, tanto la crisis económica internacional como la política a nivel nacional determinaron importantes transformaciones en Argentina. En relación con la cuestión migratoria, esto significó que las leyes pasaran a constituirse en elementos cada vez más restrictivos. Mientras tanto, en el ámbito de la educación, tanto liberales como sectores de izquierda y nacionalistas intentaron que sus ideologías quedaran plasmadas en el sistema. Sin embargo, fueron únicamente los sectores nacionalistas, a través de los gobiernos de facto y conservadores, quienes tuvieron esa chance.

Hacia mediados de la década de 1940, Argentina intentó desarrollarse como un país industrializado. En ese contexto, los flujos de inmigrantes internacionales aumentaron, sobre todo, los de aquellos que provenían de Europa, intentando escapar de la pobreza generada a través de la Segunda Guerra Mundial. A su vez, continuaron los incrementos de flujos de inmigrantes provenientes de países limítrofes y aumentaron

1 La ley de Residencia, sancionada en 1902, autorizaba al poder ejecutivo a expulsar a cualquier persona extranjera que fuese considerada peligrosa, en relación con la seguridad nacional o la alteración del orden público. A su vez, prohibía el ingreso de aquellas personas cuyos antecedentes no resultaran pertinentes para las autoridades locales. Por su parte, la ley de Defensa Social sancionada hacia 1910 poseía similares características a la anterior, pero sumaba la posibilidad de identificar cuáles eran las ideologías no deseadas (Novick, 1997, pp. 92- 93). 
las migraciones internas. En relación con el papel de la educación, si bien el peronismo promocionó la generación de prácticas educativas a partir de las que intentó incorporar ciertos saberes populares, las mismas no sufrieron transformaciones radicales y, generalmente, las escuelas continuaron siendo espacios sociales homogeneizantes.

Recién hacia fines de los años cincuenta, y hasta mediados de los sesenta, surgieron corrientes críticas del sistema escolar, representadas en América Latina por autores como Paulo Freire. Ls críticas apuntaron mayoritariamente a la denuncia de las relaciones de clase que atravesaban el sistema educativo pero no abordaron las cuestiones étnicas y nacionales (Juliano,1993, p. 87). De modo que las visiones asimilacionistas continuaron siendo las preponderantes.

Durante el período de la dictadura militar (1976-1983), Argentina atravesó un proceso sumamente nefasto que se manifestó en el conjunto de sus instituciones. En materia migratoria, hacia 1981 se sancionó la Ley $\mathrm{N}^{\circ} 22.439$, conocida como Ley Videla, a partir de la cual, entre otras cosas, se facultó a la Dirección Nacional de Migraciones a deportar extranjeros sin necesidad de recurrir a los mecanismos judiciales tradicionales. En ese contexto de exclusión, los inmigrantes intentaron resistir asentándose, sobre todo, en villas de emergencia ${ }^{1}$. Paralelamente, la dictadura destruyó buena parte del sistema educativo nacional a partir del establecimiento de un autoritarismo acérrimo y a través de la pauperización general de la calidad educativa. El carácter históricamente homogeneizante de la educación argentina se reforzó e impuso, en dicho período, a través de la opresión.

En la década de 1980, más allá del retorno de la democracia, en materia migratoria permaneció vigente la Ley Videla. Sin embargo, en el ámbito educativo se produjeron importantes cambios entre los que puede mencionarse el aumento de la matrícula de estudiantes en el nivel medio. A su vez, desde fines de los años ochenta comenzó a perfilarse, en contraposición al histórico perfil de la escuela pública, gratuita y laica, la idea de una educación privatizada. Esta mutación se enmarcó en el contexto de implementación del modelo económico neoliberal, a partir del cual se profundizó notoriamente la desigualdad social, generando un aumento de las distancias entre sectores sociales.

Durante la década de 1990, se establecieron una serie de decretos y medidas que tendieron a prolongar en el tiempo el carácter restrictivo de la política migratoria. A su vez, el discurso político gubernamental estuvo enmarcado en lineamientos xenófobos que otros actores sociales se encargaron de reproducir ampliamente. Este tipo de discursos sirvió de sustento para la negación de la problematización de la realidad socioeconómica, pues la formulación de estereotipos y prejuicios respecto de los colec-

1 En Argentina se denominan como "villas de emergencia" a aquellos barrios pobres en los que las necesidades básicas de sus habitantes no se encuentran satisfechas. En otros países latinoamericanos se utilizan los términos "chabolas", "comunas" o "favelas" con significados similares. 
tivos migratorios provenientes, sobre todo, de países limítrofes y de Perú, pero también del continente asiático y europeos de la región del este, entre otros, pemitió señalar a esta población como la responsable de la mayor parte de los problemas sociales generados a través de la consolidación del neoliberalismo.

En relación con el ámbito específico de la ciudad de Buenos Aires, en el año 1999 se sancionó la Ley N $\mathrm{N}^{\mathrm{2}}$ 203, a partir de la cual se estableció que los menores de 18 años podían ser inscritos en los establecimientos educativos así no contaran con un documento de identidad. Esta ley representó un avance, en relación con el tratamiento que los niños y jóvenes inmigrantes recibían del Estado. Paralelamente, marcó un rumbo ideológico caracterizado por la generación de políticas que favorecieron una mayor apertura hacia los colectivos de inmigrantes.

Por otro lado, también durante la década de 1990, en el ámbito educativo se pusieron en marcha algunas experiencias de reconocimiento de la diversidad cultural. Las mismas se enmarcaron en los discursos y políticas multiculturales que en aquel período se consolidaron a nivel internacional. Efectivamente, en las últimas décadas ha tenido lugar una serie de transformaciones en los discursos sobre el reconocimiento de la diversidad cultural y las políticas de identidad. Estas innovaciones se enmarcaron en las críticas al Estado moderno realizadas por distintos grupos étnicos y minorías sociales que denunciaron que el mismo instauró un tipo ideal de ciudadano subestimando la diversidad cultural, dejando de lado a las minorías y sometiéndolas a procesos de asimilación. Por aquellos años, numerosos países comenzaron a promover el respeto por la multiculturalidad que caracterizaba a sus sociedades, mientras que múltiples organismos internacionales se encargaron de difundir consignas vinculadas a la atención de la diversidad cultural.

Luego de la crisis económica, política y social desatada en 2001 y a partir de los intentos por consolidar un nuevo modelo de desarrollo, desde el sector político gubernamental se incrementaron las propuestas que promocionaron una mayor integración de los inmigrantes. Pues bien, en el 2003 se sancionó una nueva ley de migraciones $\left(\mathrm{N}^{\mathrm{o}} 25.871\right)$, caracterizada por el reconocimiento de los derechos humanos de esta población.

Mucho tiempo ha transcurrido desde la época de la inmigración de masas y de la elaboración del mandato de homogeneización que recibió la escuela. La sociedad argentina sufrió numerosas transformaciones; sin embargo, la mayor parte de las veces, el discurso político gubernamental ha mantenido su carácter pro europeo y ha ido delineando importantes rasgos discriminatorios respecto del resto de los inmigrantes. Paralelamente, en el sistema educativo, se ha masificado la educación de nivel primario, se ha expandido notoriamente la matrícula en el nivel medio y se ha registrado un progresivo aumento en el nivel universitario. Además, las transformaciones acaecidas en los últimos años han configurado un nuevo escenario en el cual se propone un nuevo 
tratamiento respecto de los inmigrantes. La Ley de Educación Nacional No 26.206, sancionada en 2006, sostiene que de acuerdo con lo establecido en la Ley de Migraciones $\mathrm{N}^{\circ}$ 25.871, el Estado debe garantizar el acceso a todos los niveles del sistema educativo, a la población inmigrante que no cuente con un documento de identidad, aceptando la presentación de documentos emitidos por sus países de origen.

En este contexto se inscriben las escuelas visitadas y, en consecuencia, los tratamientos que elaboran los docentes respecto de los jóvenes inmigrantes. A lo largo de este escrito se dará cuenta de las distintas prácticas sociales a las que se han atendido a través del trabajo de campo y se reflexionará acerca de las continuidades y variaciones evidenciadas entre las mismas y las históricas prácticas educativas asimilacionistas.

\section{Metodología}

\section{Enfoque etnográfico}

En esta investigación se ha seguido un enfoque etnográfico, continuando con los lineamientos teóricos propuestos por Rockwell (2009, p. 25), para quien una investigación de este tipo debe contar con los siguientes atributos: una permanencia extendida del investigador en el espacio social que se disponga a estudiar; la interacción con los sujetos que habitan en él; la elaboración de un producto final de tipo descriptivo en el que se incorpore la realidad social, hasta ese momento no documentada y los conocimientos locales; y un trabajo autoreflexivo que habilite al investigador para esclarecer la concepción desde la cual realiza su trabajo de observación y descripción. Durante la realización del trabajo de campo se ha atendido a las percepciones y vivencias de múltiples actores implicados en las experiencias formativas (estudiantes, docentes, autoridades de la escuela, familiares, entre otros) y al significado que le atribuyen a sus acciones. De esta manera, se procuró apreciar las distintas prácticas relacionales que se manifiestan a diario en los espacios sociales visitados y atender a las experiencias y estrategias que los sujetos construyen en cada contexto en particular.

Paralelamente, este trabajo se propuso contextualizar dichos espacios, es decir, analizar los procesos sociales que configuran las relaciones sociales que tienen lugar en sus interiores. De modo que ha resultado ineludible atender a las características y problemáticas del barrio en el que se realizó la investigación, a su historia y a la de las escuelas visitadas, a las trayectorias migratorias, escolares y laborales de los estudiantes y sus familias, y al contexto más amplio de los proyectos económicos nacionales, las políticas públicas y los discursos político gubernamentales referidos a los migrantes y la educación.

Desde los inicios del trabajo de campo en el año 2008, se han realizado observaciones con distintos grados de participación en las clases, recreos, actos escolares, en los momentos de entrada y salida de los estudiantes de los establecimientos educativos visitados y en distintos espacios que forman parte del barrio, como son, los apoyos

Para citar este artículo:
Beheran, M. (junio, 2012). Tratamientos a la población inmigrante en escuelas de nivel medio de Buenos Aires. Ánfora, 19 (32), 49 - 68. Universidad Autónoma de Manizales. ISSN 0121-6538. 
escolares. A su vez se han realizado entrevistas y mantenido conversaciones informales con diversos informantes: autoridades de las escuelas, docentes, preceptores, personal administrativo y de maestranza, padres, madres, estudiantes y miembros de las organizaciones barriales, entre otros. Paralelamente, la autora de esta investigación ha coordinado grupos focales constituidos por estudiantes y organizado una serie de talleres sobre diversos temas. En total se vistaron doce cursos, se entrevistaron formalmente a los directores de ambas escuelas, a cuarenta y tres profesores y a ocho preceptores. Además, en numerosas ocasiones se mantuvieron charlas informales con ellos, con otros docentes y con trabajadores administrativos y de maestranza. A su vez, se entrevistaron formalmente a noventa y ocho jóvenes y se mantuvieron charlas informales con ellos y con otros estudiantes.

Para analizar las experiencias formativas escolares fue necesario atender a las prácticas educativas y los modos de relación que construyen docentes y estudiantes, entendiendo que las mismas se enmarcan en múltiples maneras de pensar acerca de los sentidos de la educación y la diversidad de orígenes nacionales y pertenencias étnicas de los jóvenes. A su vez, para alcanzar los objetivos planteados a lo largo de la investigación ha sido necesario considerar las transformaciones que han ocurrido en los últimos años en el ámbito de la escuela media, en la cual se ha combinado un notorio incremento de la matrícula y la incorporación de nuevos sectores sociales, con la escasez de recursos destinados al área (Dussel, 2009, pp. 42-44).

Para Guber, "Adoptar un enfoque etnográfico es elaborar una representación coherente de lo que piensan y dicen los nativos, de modo que esa 'descripción' no es ni el mundo de los nativos, ni cómo es el mundo para ellos, sino una conclusión interpretativa que elabora el investigador" (2001, p. 15). Pues bien, para llevar a cabo el análisis de la información recabada, se procedió a su contextualización e interpretación, atendiendo continuamente a la visión construida por los sujetos intervinientes en las situaciones de investigación registradas. El foco del análisis estuvo puesto en las narrativas y en la identificación de ejes estructurantes y núcleos de significado.

\section{Las escuelas visitadas}

El trabajo de campo de tipo etnográfico se realizó entre 2008 y 2011 en dos escuelas públicas de nivel medio. Ambas se ubican en un barrio de la zona sur de Buenos Aires, en el que reside un alto porcentaje de inmigrantes procedentes, sobre todo, de Bolivia y Paraguay. A lo largo de este escrito podrá observarse que las situaciones de investigación son analizadas en clave comparativa, pues se ha atendido a cuantiosas diferencias relativas a las experiencias formativas que tienen lugar en cada uno de los espacios escolares.

En febrero de 2008 se comenzó la visita de una de las escuelas, la que será identificada como escuela A. Se trata de una escuela técnica, con especializaciones en cons-

Para citar este artículo:
Beheran, M. (junio, 2012). Tratamientos a la población inmigrante en escuelas de nivel medio de Buenos Aires. Ánfora, 19 (32), 49 - 68. Universidad Autónoma de Manizales. ISSN 0121-6538. 
trucciones y electrónica, que cuenta además con una división de modalidad bachiller. En ella funcionan tres turnos (mañana, tarde y noche); las visitas fueron realizadas durante el transcurso del turno mañana.

En la escuela B, el trabajo de campo se realizó entre los años 2010 y 2011. Se trata de un espacio escolar nocturno con modalidades bachiller y comercial, perteneciente a las conocidas como "escuelas EMEM" (Escuelas Municipales de Educación Media), creadas en la década de 1990 en el ámbito de la ciudad de Buenos Aires con el objetivo de alcanzar, en palabras de Tiramonti, "la contención afectiva y efectiva de la matrícula" (2009, p. 34). Para la autora, la iniciativa proponía una serie de transformaciones relativas a la organización de las escuelas; surgió el cargo del asesor pedagógico, se estableció una cantidad determinada de estudiantes por docente, entre otras. Sin embargo, la misma ha señalado que no todas esas propuestas se llevaron a cabo. Las autoridades y docentes de la escuela coinciden con lo señalado por Tiramonti; según manifiestan, si bien desde la institución se ha intentado implementar una organización que les permita a los docentes tener un trato más cercano y personalizado con los estudiantes y sus familias, ha resultado imposible garantizar, por ejemplo, un número más reducido de estudiantes por curso. Tanto las autoridades como la mayor parte de los profesores sostienen que la demanda de vacantes se ha incrementado en los últimos años como consecuencia de cierto mejoramiento de las condiciones sociales de las familias del barrio y frente a la ausencia de otra escuela nocturna en la zona.

La mayor parte de la población de las dos escuelas reside en una villa de emergencia ubicada en frente a ambas; cada una de ellas se ubica en un acceso distinto a la villa. De modo que las vidas de estos estudiantes transcurren en un contexto caracterizado por la desigualdad social. En la villa señalada el $30 \%$ de la población es boliviana mientras que el 15\% es paraguaya ${ }^{1}$. A las dos concurren numerosos jóvenes inmigrantes.

\section{Resultados}

Esta investigación doctoral ha permitido atender a la implementación de una perspectiva asimilacionista en la mayor parte de las prácticas educativas de la escuela A y a la preponderancia de prácticas afectivas (Abramowski, 2010, pp. 53-54) desarrolladas en la escuela B. Las primeras conciben a la otredad como algo que debe ser borrado y sobre lo cual deben imprimirse los saberes, costumbres y valores de la cultura dominante. De modo que frente a la diversidad de pertenencias étnicas y orígenes nacionales de los jóvenes, la mayor parte de los docentes apuesta por una enseñanza homogeneizante. Este tipo de situaciones es evidente a través de las observaciones de clases de distintas materias curriculares y de los estilos pedagógicos y didácticos que el cuerpo

Unidad de Gestión de Intervención Social (UGIS). 2007. Relevamiento Poblacional según Lugar de Nacimiento. Buenos Aires.

Para citar este artículo:
Beheran, M. (junio, 2012). Tratamientos a la población inmigrante en escuelas de nivel medio de Buenos Aires. Ánfora, 19 (32), 49 - 68. Universidad Autónoma de Manizales. ISSN 0121-6538. 
docente, generalmente, implementa en el aula. Pues bien, en la mayor parte de las situaciones de clase observadas, se ha percibido una notoria distancia entre las propuestas docentes y las respuestas que construyen los estudiantes.

Uno de los ejemplos que refleja este tipo de distancias puede ser apreciado a partir del registro de campo que se reproduce a continuación. El mismo corresponde a una clase de Educación Cívica de un primer año de la escuela A, en la que se abordó la temática referida a las migraciones internacionales a Argentina.

La profesora pregunta al conjunto de la clase acerca de los motivos que impulsaron a los inmigrantes de mediados del siglo XIX y principios del siglo XX a dirigirse hacia Argentina.

Paula, una estudiante argentina de 14 años señala: "Venían en barcos escapando de la guerra".

La docente agrega: 'Claro, era toda gente muy pobre'.

Me sorprende que la profesora no intervenga precisando las características de aquel momento histórico y corrigiendo a la estudiante que, seguramente, se refería a la migración masiva que tuvo lugar hacia Argentina después de la Segunda Guerra Mundial.

Jorge, un joven boliviano de 13 años agrega: 'Porque quieren un mejor futuro para sus hijos'.

La docente no retoma el comentario del estudiante y señala que: "En Argentina todos somos hijos o nietos de algún inmigrante europeo que vino con lo puesto a construir esta gran nación. El país siempre le abrió las puertas a todos aquellos hombres que quisieron venir a trabajar y hacer grande a este país. Somos lo que somos gracias a esos inmigrantes que vinieron en el pasado".

En el registro se observa la valoración que realiza la docente respecto de la inmigración europea llegada al país desde mediados del siglo XIX, rescatando su participación en la construcción de "esta gran nación” y sin mencionar los problemas que debieron enfrentar aquellos inmigrantes para integrarse a la sociedad receptora. Paralelamente, en su discurso omite señalar la presencia de inmigrantes limítrofes en el territorio argentino. Además, el tratamiento que elabora respecto de la temática inhabilita la posibilidad de reflexionar acerca de ella como un fenómeno social contemporáneo; refiere a las migraciones internacionales, únicamente, en términos históricos. A través de los modos en que aborda el tema, el mismo parece tener poco o nada que ver con las historias de vida de los estudiantes. A su vez, en los momentos en que éstos participan, como en el caso de Jorge que ante la pregunta acerca de los motivos que impulsaron a los antiguos inmigrantes a dirigirse hacia Argentina responde con una referencia al presente ("Porque quieren un mejor futuro para sus hijos"), la profesora no retoma dicha afirmación. Tampoco corrige a Paula, lo cual evidencia, entre múltiples cuestiones, el modo en que construye la práctica educativa, evadiendo los saberes previos de los estudiantes 
y sosteniendo un discurso cerrado del que parece no poder establecerse ningún cuestionamiento. Si bien las manifestaciones docentes intercalan visiones asimilacionistas, con otras que promueven la no discriminación y la integración de los inmigrantes, las prácticas educativas de la escuela A están, generalmente, vinculadas a una visión asimilacionista y normalizadora.

Paralelamente, en la escuela señalada, incluso entre algunos docentes que manifiestan preocupación en torno a la escolaridad de los estudiantes provenientes de otros países, se ha atendido a numerosas expresiones estereotipadas y prejuiciosas respecto de ellos. Algunas de las que se han registrado son las siguientes:

Estos chicos (refiriéndose a los jóvenes paraguayos y bolivianos) carecen de normas básicas de convivencia.

Los bolivianos viven hacinados, se explotan entre ellos mismos, los hijos están todo el día solos encerrados en sus casas. ¿Qué se puede esperar de ellos?

Los paraguayos son de naturaleza violenta... Siempre se andan acuhillando acá en el barrio... Además son muy promiscuos y eso les trae muchos problemas.

Estas sugestivas manifestaciones se sustentan en ideas fuertemente arraigadas entre amplios sectores de la sociedad argentina y son comúnmente reproducidas por distintos actores sociales. Si bien en los últimos años el contexto de promoción de los derechos humanos de los inmigrantes permitió que, en ciertas oportunidades y determinados espacios sociales, disminuyeran las prácticas discriminatorias, las mismas continúan reproduciéndose y son manifestadas por múltiples actores sociales.

Como se ha señalado anteriormente, durante la década de 1990, frente a las problemáticas generadas a partir de la consolidación del proyecto económico neoliberal, los inmigrantes se convirtieron en un auténtico chivo expiatorio. En ese contexto, tuvo lugar la aparición de un nuevo sistema de visibilidad de la etnicidad, a partir del cual se produjo el pasaje “(...) de una situación de invisibilización de la 'diversidad' a una creciente hipervisibilización de las diferencias” (Grimson, 2006, p. 70). Grimson se ha preguntado por qué la misma se construyó, casi exclusivamente, respecto del colectivo migratorio boliviano y no de los colectivos chileno o uruguayo, por ejemplo. Pues bien, el autor ha sostenido que dicho proceso tuvo lugar en Argentina porque ésta, históricamente, se ha imaginado a sí misma como un enclave europeo, negando la presencia de comunidades aborígenes y población africana. Dentro de este imaginario, los inmigrantes bolivianos, y sus descendientes, son identificados como esa alteridad indígena que, a lo largo de la historia, se ha intentado negar sistemáticamente.

Algunas de esas situaciones, forjadas en aquel complejo período de los años noventa, aún son palpables en la realidad social nacional. Si bien en los últimos años, se ha registrado un mejoramiento de las condiciones socioeconómicas y la disminución del desempleo, las consecuencias del neoliberalismo continúan siendo experimentadas por amplios sectores de la sociedad. En consecuencia, en ocasiones, las manifestaciones 
xenófobas siguen siendo elaboradas por algunos actores sociales y, recientemente, han vuelto a ser expresadas a través de un discurso político gubernamental, en este caso en el de autoridades de Buenos Aires, en ocasión del violento desalojo de un grupo de vecinos que habían tomado terrenos del llamado Parque Indoamericano de la ciudad de Buenos Aires, ubicado en las cercanías de las escuelas en las que se realiza la investigación de la cual se desprende este artículo 1 .

Los tratamientos docentes respecto de los jóvenes inmigrantes que asisten a las escuelas visitadas se enmarcan en ese contexto. De modo que muchas de esas visiones y experiencias se reproducen en los espacios escolares a través de las representaciones y prácticas de docentes, autoridades y estudiantes. El trabajo de campo ha permitido encontrar que, más allá de las preocupaciones que señalan algunos docentes de la escuela A en relación con la escolaridad de estos jóvenes, sus representaciones sociales y prácticas educativas se inscriben en esa perspectiva que ve, generalmente, en la diversidad de orígenes nacionales y pertenencias étnicas, una desventaja.

Ahora bien, en ocasiones, los docentes que se muestran preocupados acerca de cómo integrar a los jóvenes inmigrantes, ponen en marcha algunas estrategias educativas que, allende las buenas intenciones, suelen generar complejos resultados. Pues bien, en una clase abierta de Historia para padres, madres y estudiantes de $2^{\circ}$ año de la escuela A, el tema de la clase era Pueblos indígenas y la idea de invitar a las familias de los estudiantes había sido propuesta por la docente de Historia quien, según explicó, entendía que era una excelente oportunidad "para promover el reconocimiento de las culturas indígenas de las cuales provienen muchos alumnos de la escuela". A continuación, se reproducen algunas partes del registro elaborado luego de observar aquel encuentro.

La clase comenzó con la exhibición de un video de fotografías, editado por el Ministerio de Educación nacional, "sobre las distintas culturas indígenas y sus costumbres", según señaló la docente. Mientras se proyectaba el video, la misma explicaba qué se veía en cada una de las fotos. Los jóvenes escuchaban en silencio. Algunas madres hablaban entre ellas. Sólo había un padre, que permaneció en silencio durante toda la clase.

Una de las fotos era sobre la celebración de la Pachamama. En la imagen podía observarse una botella de cerveza de la marca Quilmes. En ese momento, uno de los estudiantes dijo: "Está mal que no hayan sacado la botella, eso no es de la cultura indígena". Ni la docente, ni ningún otro de los asistentes retomó el comentario del joven.

1 El desalojo de los vecinos tuvo lugar de manera violenta y contó con la represión de las policías Federal y Metropolitana. Como resultado, dos personas murieron y numerosas resultaron heridas. En ese contexto, el Jefe de Gobierno Porteño, Mauricio Macri, el Jefe de Gabinete, Horacio Rodríguez Larreta y la Diputada Gabriela Michetti declararon públicamente una serie de manifestaciones xenófobas en las cuales vincularon a los inmigrantes con la delincuencia y el narcotráfico. 
Cuando finalizó la exhibición, la docente les preguntó a todos qué les había parecido el video. Algunas madres señalaron las siguientes manifestaciones:

"Los chicos no valoran...no le dan valor a la cultura de sus antepasados".

"Les da vergüenza que hablemos sobre este tema".

"En mi familia nunca tuvimos vergüenza de decir nuestras costumbres pero a los chicos no les pidas lo mismo porque no quieren saber nada con eso".

La docente no retomaba ninguno de los comentarios que hacían las madres e invitaba a los estudiantes a que participaran, diciéndoles que no tuviesen vergüenza. Una madre sostuvo que, probablemente, entre los motivos de esa vergüenza se encontraba la discriminación que sufren, en ocasiones, los jóvenes "por tener rasgos indígenas". Otra madre señaló: "Yo siempre le digo a ella (dirigiéndose a su hija) que es india... porque el padre lo es ... tenemos antepasados... y ella me dice que no".

Frente a este comentario, dejando ver su enojo, la joven exclamó: “¡Yo no soy india, mamá!". Su madre le respondió, riéndose: "Sí, lo sos".

Una de las situaciones que resulta llamativa es la escasa, o por momentos nula, atención que la docente le otorgaba a los comentarios de los presentes. El único comentario al que atendió, aunque sin problematizarlo, fue el referido a la supuesta vergüenza que los jóvenes sentían frente al tratamiento de la temática. En ese momento, los invitó a que participaran. Sin embargo, ante las manifestaciones como la del joven que señaló sorprendido que en un video sobre indígenas apareciera una botella de cerveza, la docente no pareció identificar una posibilidad, o no le interesó hacerlo, para rastraer qué significados construyen los estudiantes y sus familias respecto de lo indígena, sobre lo que es y no es aborigen. El comentario del joven parecía estar construido a través de imágenes que las escuelas, los manuales escolares y el pensamiento hegemónico en general se han encargado de difundir ampliamente, en las que se asocia lo indígena con el pasado; en ese imaginario, que parecía recrear el joven con su comentario, no podía caber la imagen de una botella de cerveza.

Otra de las situaciones que resulta sorprendente es la casi compulsiva marcación de la ascendencia indígena que realizaban algunas madres respecto de sus hijos. Paralelamente, sólo una de ellas mencionó la posibilidad de que la "vergüenza" que, supuestamente, sienten los jóvenes "por tener rasgos indígenas" estuviese forjada en el contexto discriminatorio en el que viven. Novaro ha sostenido que: “(...) nombrar al otro no sólo es una forma de reconocerlo, sino que tambien puede ser una forma de marcación en tanto un término (indio, hablante de una lengua indígena, boliviano) lleva asociado un significado peyorativo que se impone sobre alguien" (2010, pp. 188-189). La propuesta de la autora referida a cómo nombrar puede significar marcar, cuando los nombres están cargados de connotaciones despectivas, puede aplicarse a la compresión de los silencios de estos jóvenes, del ocultamiento de las cuestiones étnicas, que tal vez hayan tenido otros significados entre otros miembros de sus familias y de los fuertes y

Para citar este artículo:
Beheran, M. (junio, 2012). Tratamientos a la población inmigrante en escuelas de nivel medio de Buenos Aires. Ánfora, 19 (32), 49 - 68. Universidad Autónoma de Manizales. ISSN 0121-6538. 
por momentos angustiantes procesos de desmarcación que elaboran, como en el caso de la joven que con un notorio enojo exclamó: “¡Yo no soy india, mamá!".

En la escuela B las experiencias formativas de los estudiantes son notoriamente diferentes a las que vivencian los que asisten a la escuela A. Los tratamientos están caracterizados, generalmente, por prácticas afectivas (Abramowski, 2010, pp. 53-54). Desde la dirección de la escuela se promueve la importancia de las características relacionales y afectivas de las prácticas educativas. La directora del establecimiento ha señalado que uno de los objetivos centrales de la escuela es "construir un vínculo afectivo entre la escuela y los estudiantes... que los estudiantes sepan que acá se puede hablar de todo y que cuando tienen un problema vienen y se charla". A través de las visitas realizadas al establecimiento educativo se ha observado que, en concordancia con esas expresiones, todas las tardes cuando los estudiantes ingresan en él, la directora los recibe en la entrada. Muchos jóvenes se acercan a darle un beso y, en numerosas ocasiones, ella los saluda llamándolos por sus nombres. A su vez, en las clases observadas se ha atendido a vínculos de confianza y afecto entre docentes y estudiantes. En varias oportunidades, numerosos profesores han demostrado conocer no sólo el nombre y apellido de los jóvenes sino también la composición de sus familias, de qué trabajan su padre y/o madre, si ellos trabajan y, en el caso de los inmigrantes, sus orígenes nacionales y partes de sus trayectorias migratorias.

A continuación se reproducen fragmentos de los registros de campo en los que se evidencian algunas de esas situaciones. Los mismos fueron elaborados luego de observar una clase de Geografía de $5^{\circ}$ año.

Estela, la docente, y yo nos encontrábamos charlando en el aula. Los estudiantes iban llegando y luego de saludarnos a ambas con un beso se ubicaban en sus mesas. En el aula hay cinco mesas con cuatro sillas alrededor, en las que se sientan los jóvenes.

Estela inició un diálogo con los chicos intercambiando comentarios sobre diversos temas; algunas chicas señalaban que estaban cansadas, que habían trabajado durante todo el día y que tenían "ganas de hacer nada". Un estudiante comentó que tenía hambre y aclaró que no había comido durante todo el día. Luego, le preguntó a sus compañeros si tenían algo para comer. Estela le explicó, amablemente, que en un momento traerían la merienda. El diálogo continuó unos minutos más y rápidamente la docente se dispuso a comenzar la clase con el tema del día. En ese momento todos terminaron de ubicarse en sus asientos y abrieron sus carpetas.

En el registro puede observarse el clima de cordialidad en el que transcurrió la clase. Desde ya no se descarta que, en ocasiones, puedan tener lugar situaciones menos amables. Sin embargo, en comparación con las observaciones realizadas en la escuela A, no se ha atendido a momentos de tensión entre los distintos participantes del espacio escolar sino, por el contrario, a escenarios en los que preponderaban las relaciones de amabilidad y respeto. 
Por otro lado, durante las clases, numerosos docentes de la escuela apelan a la cotidianidad en la que viven los estudiantes para buscar ejemplos relativos al tema que se encuentran explicando. En el siguiente registro se observa el uso que la docente de Geografía realizaba en una clase, respecto de las experiencias laborales de los jóvenes.

Estela explicaba el concepto de movilidad social y hacía referencia a las dificultades que suelen caracterizar a las trayectorias laborales en la actualidad. Para dar cuenta de su idea, les preguntó a los estudiantes acerca de sus experiencias y expectativas laborales. Soledad, una joven boliviana de 17 años, respondió nombrando múltiples experiencias laborales que había vivenciado. Todas ellas vinculadas a empleos no calificados e inestables y algunas vinculadas al trabajo en talleres textiles regenteados por miembros de su familia. Luego relató su experiencia actual como pasante en un centro de salud perteneciente al Gobierno de la Ciudad de Buenos Aires. Reconoció que llevaba seis meses trabajando y que aún no le habían pagado, sin embargo, sostuvo que se trata de una experiencia sumamente gratificante en la que se encuentra "haciendo algo de lo que aprendemos acá con el perito... porque hacemos trabajo administrativo... y eso me gusta". Luego, pidió la palabra Luis, un joven hijo de bolivianos de 17 años de edad, quien expresó el cansancio que le producen las extensas jornadas laborales, a las que asiste junto a su hermano, en una obra en construcción.

Lo que resulta interesante rescatar de este breve registro es la apelación de la docente hacia las voces de los estudiantes, hacia sus vidas e intereses y la consecuente participación de estos a través de la exposición de sus experiencias formativas y laborales y de los complejos modos en que las vivencian. Este tipo de prácticas educativas se ubica en concordancia con las propuestas pedagógicas y didácticas que pregonan el reconocimiento y uso en los espacios educativos de los saberes previos y experiencias de los estudiantes y se contrapone al estilo y la perspectiva asimilacionista, a la que se ha atendido en las prácticas educativas preponderantes en la escuela A.

Por otro lado, y también en contraposición con lo que ocurre en la escuela A, en la escuela $\mathrm{B}$ no se ha observado que las expresiones docentes respecto de la diversidad de orígenes nacionales de los estudiantes asociaran a la misma con una desventaja. Generalmente, ante las preguntas referidas al rendimiento escolar de los chicos inmigrantes, la mayor parte de docentes recurría a una explicación de tipo social para dar cuenta de sus problemas educativos. Las situaciones de vulnerabilidad en las que viven ellos y sus familias, las experiencias laborales asociadas a la explotación que padecen y los desmembramientos que caracterizan a varias familias separadas por la migración eran algunas de las complejas situaciones que la mayor parte de docentes mencionaba a la hora de explicar los motivos que dificultan la escolaridad de estos jóvenes.

Paralelamente, afirmaban que el hecho de ser inmigrante conlleva un plus de vulnerabilidad que los expone a situaciones aún más dramáticas que las que vive el resto de los estudiantes, ya sea porque muchos de ellos no han accedido a la regularización de su situación migratoria o bien porque padecen las consecuencias de los fuertes estigmas que los colocan en posiciones de subalternidad y opresión.

Para citar este artículo:
Beheran, M. (junio, 2012). Tratamientos a la población inmigrante en escuelas de nivel medio de Buenos Aires. Ánfora, 19 (32), 49 - 68. Universidad Autónoma de Manizales. ISSN 0121-6538. 
Abramowski (2010, p. 56) ha sostenido que las prácticas que despliegan los docentes son elaboradas históricamente a través de diversos discursos pedagógicos y disciplinarios. Siguiendo la propuesta de la autora, al analizar en clave comparativa las prácticas educativas y relacionales de uno y otro espacio puede observarse cierta correspondencia entre las mismas y los discursos pedagógicos situados históricamente. Efectivamente, los distintos momentos históricos en los que se fundan las escuelas dan cuenta de la impronta asimilacionista, que caracteriza a la mayor parte de prácticas realizada en la escuela $\mathrm{A}$, o bien de la propuesta pedagógica que aboga por el reconocimiento de los saberes previos de los estudiantes y las relaciones afectivas, que tiene lugar en la escuela B. La escuela A surge a mediados de las década de 1970, en un complejo momento histórico en el que la dictadura militar se encargó de reforzar el carácter homogeneizante de la educación argentina.

Por su parte, la escuela B surge en la década de 1990, en la que en pleno auge del modelo neoliberal, desde algunos sectores se proponía la creación de escuelas innovadoras que pudieran atender a las demandas de una población altamente vulnerable y, como fue señalado anteriormente, contenerla afectivamente también dentro de la escuela, evitando así el contínuo crecimiento de la deserción escolar. A través del trabajo de campo realizado se ha atendido a que en ellas el paso de los años no parece haber trastocado los lineamientos pedagógicos fundacionales. Si bien seguramente las prácticas educativas y relacionales de ambas escuelas deben haber sufrido transformaciones, en líneas generales, las perspectivas y estilos pedagógicos parecieran continuar inmutables.

Por otro lado, en las escuelas visitadas la retórica del multiculturalismo, ampliamente difundida desde la década de 1990 en el sector educativo de nivel primario y por los organismos internacionales vinculados con la temática educacional, parece haber calado con escasa profundidad. En este sentido, entre las representaciones y prácticas docentes se han evidenciado contadas referencias a los discursos que pregonan el reconocimiento y la promoción de la diversidad cultural. Si bien los modos de relación entre docentes y estudiantes inmigrantes son distintos entre ambas escuelas, teniendo lugar en la escuela B un tratamiento mucho más ameno, en ninguno de los espacios escolares se ha atendido a prácticas educativas de tinte multicultural. En las entrevistas y charlas con los docentes de ambos establecimientos, aquellos que se manifestaban más preocupados por los estudiantes inmigrantes advertían, generalmente, acerca de la intranquilidad que les produce la deserción escolar de numerosos jóvenes y los graves problemas sociales que atraviesan las vidas de los mismos. Sin embargo, no identificaban necesidades relativas a la revisión de los contenidos escolares o los estilos pedagógicos o didácticos que se implementan cotidianamente en las clases.

Pues bien, a lo largo del trabajo de campo, una de las situaciones que ha resultado llamativa es la escasa reflexión crítica que tiene lugar entre los docentes respecto de 
las prácticas en las que participan y las perspectivas educativas a través de las que se elaboran las mismas. En relación con las problemáticas educativas de los jóvenes inmigrantes, en la escuela A la mayor parte de los profesores parece estar convencida de que el problema es de los otros, mientras que en la escuela $\mathrm{B}$ el foco del análisis se coloca en las situaciones de desigualdad social en las que viven los jóvenes.

De modo que en las escuelas visitadas, los tratamientos respecto de la población inmigrante oscilan entre las complejas prácticas de tinte asimilacionista y las de tipo afectivo. La escasa problematización de la retórica imperante en las escuelas sobre las migraciones a Argentina y la persistencia de miradas estereotipadas y prejuiciosas o de aquellas que se limitan a dar cuenta de las condiciones de desigualdad social en las que vive la mayor parte de los estudiantes, obstruyen las posibilidades de que tengan lugar otros tipos de prácticas. La mayor parte de los docentes no identifica la necesidad de revisar los contenidos curriculares y la perspectiva homogeneizante a través de la que se ha construido y aún se sostiene el sistema educativo nacional que todavía pregona, a través de la Ley de Educación Nacional N²6.206, la necesidad de reafirmar la identidad nacional argentina.

\section{Conclusiones}

El estudio ha permitido comprender que más allá de las transformaciones económicas, políticas, sociales y culturales ocurridas a través de la historia, las prácticas educativas asimilacionistas permancen vigentes. La retórica referida a una Argentina europeizada pervive en el imaginario de múltiples actores sociales, entre quienes numerosos docentes ocupan un llamativo y problemático lugar. Muchos de ellos, incluso algunos que se manifiestan preocupados por las dificultades educativas de los estudiantes inmigrantes, poseen visiones estereotipadas y prejuiciosas respecto de la población inmigrante proveniente de países limítrofes. Asimismo, entre las prácticas de los docentes, no obstante las buenas intenciones de algunos de ellos que manifiestan reconocer la diversidad cultural presente en los espacios escolares, acaban por generar situaciones de marcación del otro que profundizan las situaciones de estigmatización a numerosos jóvenes con diversas pertenencias étnicas y orígenes nacionales.

Paralelamente, se ha evidenciado otro tipo de tratamiento, vinculado a una visión de mayor reconocimiento y respeto de los estudiantes, que consiste en la implementación de prácticas afectivas que propician situaciones de mayor encuentro entre éstos y sus docentes. Sin embargo, entre los profesores que elaboran ese tipo de prácticas tampoco tiene lugar una mirada crítica acerca de los contenidos curriculares, por ejemplo. El mayor reconocimiento que elaboran respecto de los estudiantes y de sus complejas situaciones de vida excluye la identificación de unos contenidos curriculares que muchas veces poco tienen que ver con la diversidad de orígenes nacionales y pertenencias

66 étnicas que se observan en los espacios escolares.

Para citar este artículo:
Beheran, M. (junio, 2012). Tratamientos a la población inmigrante en escuelas de nivel medio de Buenos Aires. Ánfora, 19 (32), 49 - 68. Universidad Autónoma de Manizales. ISSN 0121-6538. 
Las prácticas asimilacionistas, la vigencia de visiones estereotipadas, la escasa reflexión crítica que realiza la mayor parte de los docentes sobre su desempeño profesional y la inexistencia de proyectos educativos elaborados por las escuelas en relación con la atención de estudiantes de diversos orígenes nacionales, constituyen un contexto escolar que se presenta dificultoso para los jóvenes inmigrantes.

Las prácticas que tienen lugar en las escuelas se inscriben en contextos sociales que las exceden y atraviesan continuamente, de modo que así como aquellas transformaciones jurídicas y políticas, en relación con el tratamiento de la población inmigrante señaladas en la introducción de este artículo, penetraron en las escuelas garantizando el acceso de muchos jóvenes inmigrantes, también en ellas aún tienen lugar miradas estereotipadas respecto de los inmigrantes limítrofes, que la sociedad argentina ha construido a lo largo de su historia y que en la actualidad perviven. Dichas transformaciones y continuidades permiten vislumbrar un horizonte complejo en el que la asimilación y la xenofobia se perfilan como problemáticas persistentes, pero en el que también se distinguen posibilidades de transformación y respeto de aquellos sujetos cuyos derechos humanos han sido consagrados por la ley. Para que esos cambios tengan lugar pareciera ser necesario que las escuelas y el sistema educativo, en general, revisen de manera crítica el relato referido a los procesos migratorios y su rol en la construcción de la nación argentina, en el cual históricamente los migrantes procedentes de países limítrofes han permanecido invisibilizados.

\section{Referencias}

Abramowski, A. (2010). Maneras de querer. Los afectos docentes en las relaciones pedagógicas. Buenos Aires: Paidós.

Benencia, R. (2003). La inmigración limítrofe. En Devoto, F. Historia de la Inmigración en la Argentina (pp. 433-484). Buenos Aires: Editorial Sudamericana,

Devoto, F. (2003). Historia de la Inmigración en la Argentina. Buenos Aires: Editorial Sudamericana.

Díez, M. y Novaro, G. (2009). ¿Una inclusión silenciosa o las sutiles formas de la discriminación? Reflexiones a propósito de la escolarización de chicos bolivianos. En Pacecca, M. y Courtis, C. (Comp.) Diagnóstico participativo sobre discriminación. Buenos Aires: Asociación por los Derechos Civiles y Editores del Puerto. En prensa.

Dussel, I. (2009). La escuela media y la producción de la desigualdad: continuidades y rupturas. En Tiramonti, G. y Montes, N. (Comp.) La escuela media en debate. Problemas actuales y perspectivas desde la investigación (pp. 38- 52). Buenos Aires: Manantial, FLACSO.

Grimson, A. (2006). Nuevas xenofobias, nuevas políticas étnicas en la Argentina. En Grimson, A. y Jelin, E. (Comp.) Migraciones regionales hacia la Argentina. Diferencia, desigualdad y derechos (pp. 69- 97). Buenos Aires: Prometeo Libros. 
Guber, R. (2001). La etnografía. Método, campo y reflexividad. Bogotá: Editorial Norma.

Juliano, D. (1993). Las minorías étnicas en Argentina. La autoreproducción social y el tratamiento escolar de la diferencia (1880-1980). Memoria de Investigación.

Neufeld, M. y Thisted, J. (Comp.) (1999). De eso no se habla... los usos de la diversidad sociocultural en la escuela. Buenos Aires: Eudeba.

Nobile, M. (2006). La discriminación de los inmigrantes en la escuela media. Un análisis de los discursos, las prácticas y los condicionantes legales. Buenos Aires: CLACSO.

Novaro, G. (2010). Niños migrantes y escuela: ¿Identidades y saberes en disputa? En Novaro, G. (Coord.) La interculturalidad en debate. Experiencias formativas y procesos de identificación en niños indígenas y migrantes (pp. 179- 203). Buenos Aires: Editorial Biblos,

Novick, S. (1997). Políticas migratorias en la Argentina. En Oteiza, E. Novick, S. y Aruj, R. (Comp.) Inmigración y Discriminación. Políticas y Discursos (pp. 83-165). Buenos Aires: Grupo Editor Universitario.

Rockwell, E. (2009). La experiencia etnográfica: historia y cultura en los procesos educativos. Buenos Aires: Paidós.

Tiramonti, G. (2009). Una aproximación a la dinámica de la fragmentación del sistema educativo argentino. Especificaciones teóricas y empíricas. En Tiramonti, G. y Montes, N. (Comp.) La escuela media en debate. Problemas actuales y perspectivas desde la investigación (pp. 25 - 38). Buenos Aires: Manantial - FLACSO.

Unidad de Gestión de Intervención Social -UGIS- (2007). Relevamiento Poblacional. según Lugar de Nacimiento. Buenos Aires.

Para $\quad$ Beheran, M. (junio, 2012). Tratamientos a la población inmigrante en escuelas de nivel me- 